\title{
Dr Philip Burnard Chenery Ayres and the plague fighters of the Government Civil Hospital
}

TW Wong, FHKAM (Emergency Medicine)

Member of the Education and Research Committee, Hong Kong Museum of Medical Sciences Society

https://doi.org/10.12809/hkmj-hkmms202108

The bubonic plague epidemic in 1894 was one of the most important events in the history of Hong Kong. It took more than 2500 lives among a population of around 200000 at the time, and dealt a severe blow to the economy of the colony. Dr Philip Burnard Chenery Ayres (1840-1899) was leading the fight against this horrible epidemic as Colonial Surgeon and a member of the Sanitary Board. Initially, he had help from only Dr James Lowson, who was the acting medical superintendent of the Government Civil Hospital (GCH). A temporary hospital was set up at Kennedy Town to accommodate the patients with plague. Different staff groups from the $\mathrm{GCH}$ were also rotated to this hospital to cope with the patient load. There were plague outbreaks in Hong Kong almost every year for the subsequent three decades, and many public health measures were introduced to try to curb this threat.

This is a picture of the staff of the $\mathrm{GCH}$ probably taken in 1897 before the retirement of Dr Ayres (Fig). The Civil Hospital was situated at Hospital Road, Sai Ying Pun, and was the only major government hospital in the colony before it was replaced by Queen Mary Hospital in 1937. It mainly served the European population and civil servants. Local Chinese residents would prefer Tung Wah Hospital and the hospitals run by the London Missionary Society, Alice Memorial Hospital and Nethersole Hospital.

Dr Ayres was the longest serving as well as the last Colonial Surgeon of Hong Kong. He came to Hong Kong from India in 1873 to take up the post of Colonial Surgeon and stayed in the post for 24 years. ${ }^{1} \mathrm{He}$ was in the limelight in 1894, when the bubonic plague swept through Hong Kong. This was an epidemic he had predicted 20 years previously. After arriving in Hong Kong in 1873, he visited the Chinese districts and found the crowded and unsanitary living conditions of the lower social classes quite alarming. He subsequently reported his findings to the government and recommended public health measures to improve the conditions. ${ }^{2}$ Unfortunately, his report was suppressed and relatively little was done to improve the poor living

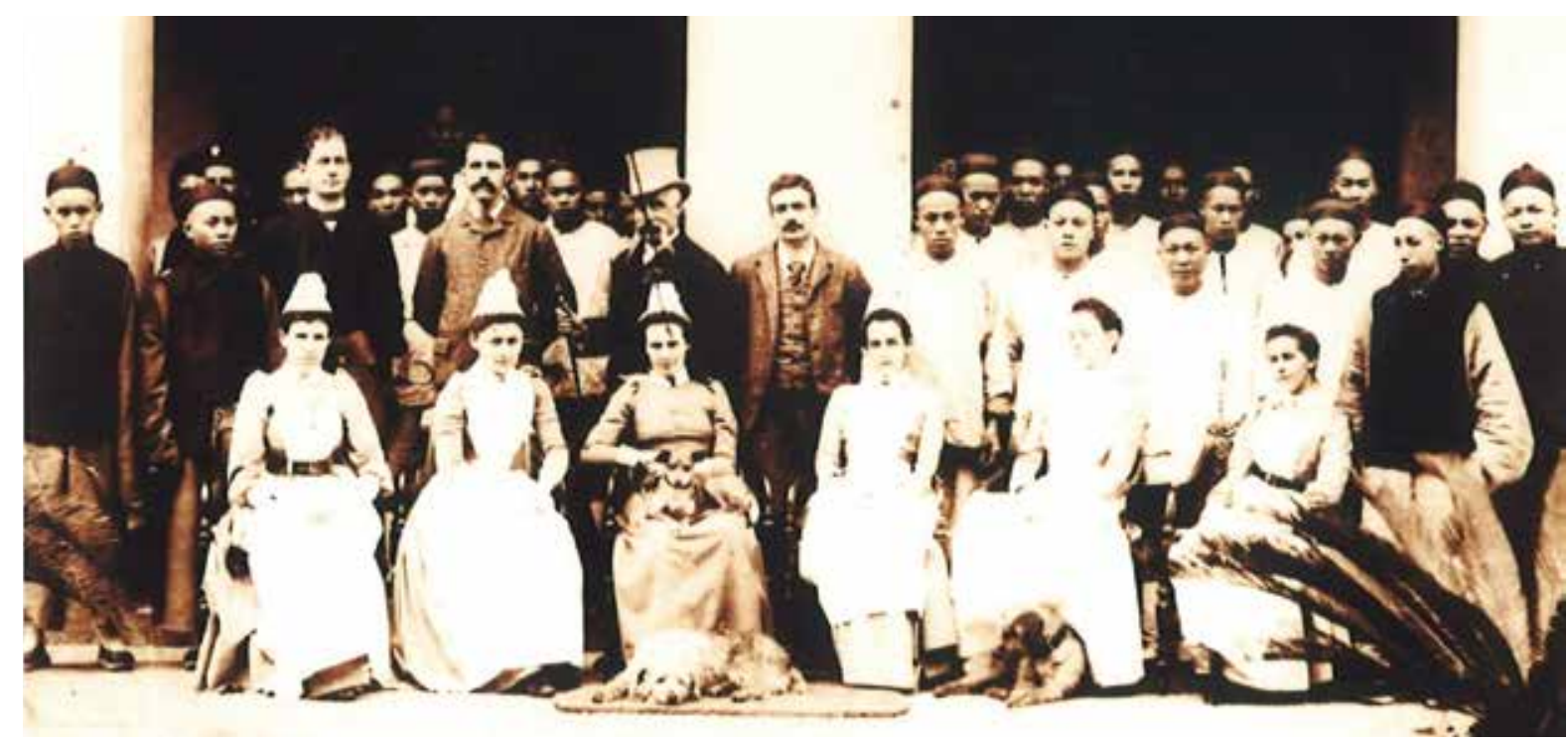

FIG. A group photograph of Dr Philip Burnard Chenery Ayres and staff at the Government Civil Hospital. Dr Ayres (with a top hat) is standing in the centre with Dr John Mitford Atkinson to his right. Sitting in the front row were the nursing Sisters. The photograph was kindly donated to the Hong Kong Museum of Medical Sciences in 1996 by Mrs FM Ashburner, granddaughter of Dr James Lowson 
conditions. It was not until 1881 when the Colonial Service in London agreed to send Osbert Chadwick to look into the state of sanitation in Hong Kong, and Dr Ayres was vindicated. In his report in 1882, Mr Chadwick recommended measures to improve the Chinese tenement houses, drainage, and water supply. A Sanitary Board was formed in 1883 to oversee sanitary matters and Dr Ayres was a member of the board in his capacity as Colonial Surgeon. During his long term at the colonial medical services, he had improved mental health services by building proper lunatic asylums; appointed a colonial veterinary surgeon to safeguard public health; and created a vaccine institute that produced enough smallpox vaccine to cover the population. He died in the United Kingdom in 1899 just 2 years after he left Hong Kong. ${ }^{1}$

The plague of 1894 had led to the introduction of a Medical Officer of Health to oversee sanitary matters and the reorganisation of the medical department to improve its capacity to deal with future epidemics. The title of Colonial Surgeon was thus changed, and Dr John Mitford Atkinson was appointed as the first Principal Civil Medical Officer. ${ }^{3}$ Dr Atkinson came to Hong Kong in 1887 to be Medical Superintendent of the Civil Hospital. He was on leave in England during the 1894 bubonic plague epidemic. In later years, he played a significant role in the combat of plague as Principal Civil Medical Officer of the colony. He became an expert in tropical medicine and on his retirement in 1912, after a quarter of a century in Hong Kong, he entered private practice in London. One of his best remembered legacies was the introduction of trained nurses in the Civil Hospital. ${ }^{4,5}$

In Hong Kong in 1887, there were no trained nurses in the Civil Hospital. There were two
European Wardmasters who were supervising untrained Chinese attendants to provide care for the patients. The state of care was far from satisfactory, and Dr Atkinson petitioned to the government for recruitment of trained nurses from England. Through his connection to London Hospital, eventually five Sisters led by a Matron (Clara Eastmond, who later became Mrs Atkinson in 1898) joined the Civil Hospital in $1890 .^{6}$ During the plague in 1894 , the nursing Sisters volunteered their services to the temporary plague hospitals in Kennedy Town. Their hard work was highly praised by Dr Lowson who was in charge of the medical response. In his report on the 1894 plague epidemic, he said, "If ever this colony has had reason to congratulate itself it was when we were able to procure well-trained British nurses. I think the greatest compliment that I can pay these ladies is to say that had it not been for their presence there could have been no well-run epidemic hospital during last summer."7 The Sisters were awarded gold medals for their services during the bubonic plague in $1894 .{ }^{8}$ Unfortunately, two of the Sisters (Elizabeth Frances Higgins and Emma Gertrude Ireland) contracted plague and died in 1898. They were buried in the Hong Kong Cemetery and stained-glass windows were put up in St John's Cathedral in their memory. ${ }^{9}$

Other staff present in the photograph include European apothecaries and their Chinese assistants and students. The Wardmaster and Steward were Europeans and they had a few Chinese clerks to assist them. Chinese in white uniforms were probably untrained nurses who worked under the Sisters. Dr James Lowson was not in the photograph because he was invited by the Government of India to be special plague commissioner and adviser in 1897.

\section{References}

1. Obituary: Philip B. C. Ayres, C.M.G., M.R.C.S. Br Med J 1899;2:1140.

2. Ayres PB. Hong Kong Colonial Surgeon's Report for 1880. 20 May 1881.

3. Chan-Yeung M. A Medical History of Hong Kong: 1842-1941. The Chinese University of Hong Kong Press; $2018:$ 166-7.

4. Obituary: John Mitford Atkinson, M.B.Lond. Br Med J 1917;1:827.

5. Obituary: John Mitford Atkinson, M.B.(Lond). Trans R Soc Trop Med Hyg 1917;10:207-9.

6. Stratton D. History of nursing in government hospitals. Hong Kong J Nursing 1972;May:34-7.

7. Lowson J. The epidemic of bubonic plague in Hongkong, 1894. Hongkong Government Gazette, 13 April 1895.

8. Chan-Yeung M, Poon KW. The Hong Kong Plague Medal. Hong Kong Med J 2017;23:319-20.

9. Plague in Hong-Kong. Lancet 1899;154:514. 